1 Suter D. Hair colour in the Faroe and Orkney Islands. Ann Hum Biol 1979;6:89-93.

2 Lykken D, Tellegen A. Happiness is a stochastic phenomenon. Psychol Sci 1996;6:10-9.

3 Inglehart R, Klingemann H-D. Genes, culture, democracy, and happiness. In: Diener E, Suh EM, eds. Culture and subjective well-being. Cambridge, MA: MIT Press, 2000:165-83.

4 Jacobsen R, Von Euler M, Osler M, Lynge E, Keiding N. Women's death in Scandinavia-what makes Denmark different? Eur I Epidemiol 2004;19:117-21.

5 Kohler H-P, Behrman JR, Skytthe A. Partner + children = happiness. The effects of partnerships and fertility on well-being. Popul Dev Rev 2005;31:407-45.

6 Börsch-Supan A, Brugiavini A, Jürges H, Mackenbach J, Siegrist J, Weber $\mathrm{G}$, eds. Health, aging and retirement in Europe. First results from the survey of
health, aging and retirement in Europe. Mannheim: Mannheim Research health, aging and retirement in Europe. Mannheim: Mannheim Research Institute for the Economics of Aging (MEA), 2005.

7 Diener E, Diener M, Diener C. Factors predicting the subjective well-being of nations. J Pers Soc Psychol 1995;69:851-64.
8 Easterlin RA. Explaining happiness. Proc Natl Acad Sci U S A 2003; 100:11176-83.

Gini C. Variabilità e mutabilità (1912). In: Pizetti E, Salvemini T, eds. Memorie di metodologica statistica. Rome: Libreria Eredi Virgilio Veschi, 955

10 Countries by income inequality metrics based on the Gini coefficient. In: United Nations Development Programme Report. New York: UNDP Publications, 2005.

11 Kirkup W, Merrick DW. A matter of life and death: population mortality and football results.J Epidemiol Community Health 2003;57:429-32.

12 Witte DR, Bots ML, Hoes AW, Grobbee DE. Cardiovascular mortality in Dutch men during 1996 European football championship: longitudinal population study $B M J 2000 ; 321: 1552-4$.

13 Lyubomirsky S. Why are some people happier than others? The role of cognitive and motivational process in well-being. Am Psychol 2001;56:239-49

(Accepted 20 October 2006)

doi $10.1136 /$ bmj.39028.665602.55

\title{
Phenotypic differences between male physicians, surgeons, and film stars: comparative study
}

\author{
Antoni Trilla, Marta Aymerich, Antonio M Lacy, Maria J Bertran
}

We finished our medical training at the University of Barcelona more than 25 years ago, and have enjoyed our work ever since. At medical school we noted certain differences between male trainees who selected either surgery or medicine as their specialty. The tallest and most handsome male students were more likely to go for surgery, and the shortest (and perhaps not so good looking) ones were more likely to become physicians (including doctors of internal medicine and its subspecialties).

Now, after all these years we hypothesise that, on average, surgeons are taller and better looking than physicians. We conducted a comparative study to test this hypothesis.

\section{Methods}

We selected a random sample of senior staff surgeons and physicians working at the University of Barcelona Hospital Clinic (a 700 bed public hospital), matched by age (52 \pm 7 years) and sex (all men), from the staff payroll of the surgical and medical departments. We contacted all eligible participants by email. If they agreed to participate, their height (in $\mathrm{cm}$ ) was recorded and they were asked to submit a digital picture. Age (in years) was registered and checked against that recorded in the payroll database. The external controls were four well known film stars, mostly in their 50s-Harrison Ford as Dr Richard Kimble (a neurosurgeon in the film The Fugitive), George Clooney as Dr Doug Ross (a paediatrician in the television series ER), Patrick Dempsey as Dr Derek Shepherd (a surgeon in the television series Grey's Anatomy), and Hugh Laurie as Dr Gregory House (a nephrologist and infectious disease specialist in the television series House).

We randomly organised the pictures of all surgeons, physicians, and external controls and showed them to an independent group of eight female observers-three doctors and five nurses from our hospital. All observers were in the same age group as the participants (no further checking of this information was attempted). We decided to avoid (for the time being) male observers, because of potential bias. Observers used the "good looking score" to classify each participant. This score measures the degree of handsomeness on a seven point Likert scale (1, ugly; 7 , very good looking).

We discarded the highest and lowest score (outliers) for each participant and used the six remaining scores for our study. Mean scores, differences in means with $95 \%$ confidence intervals, and standard deviations were used to compare the three groups. We used the standard $t$ test to compare age and the non-parametric (Mann-Whitney U) test to compare height and mean good looking scores.

\section{Results}

We contacted 14 surgeons and 16 physicians (24 surgeons and 38 physicians were eligible). Only two surgeons and two physicians did not answer the questionnaire or send a picture (their out of office auto reply was switched on). Two additional physicians were dropped from the final analysis because of the poor quality (technical, of course) of their pictures. The final analysis therefore comprised 12 physicians and 12 surgeons plus four external controls.

The mean age of physicians was 50.6 years (SD 4.02) and of surgeons 51.1 years (SD 4.11) $(\mathrm{P}=0.76)$. The mean height of physicians was $172.6 \mathrm{~cm}(95 \%$ confidence interval 170.2 to 175.4$)$ and of surgeons $179.4 \mathrm{~cm}(175.1$ to 184.0$)(\mathrm{P}=0.01)$.

Film stars (external controls) had significantly higher good looking scores than surgeons (5.96 v 4.39; difference between means $1.57,95 \%$ confidence interval 0.69 to $2.45 ; \mathrm{P}=0.013$ ) and physicians (5.96 v $3.65 ; 2.31,1.58$ to $3.04 ; \mathrm{P}=0.003)$. Surgeons had statistically significantly higher good looking scores than physicians (4.39 $v 3.65 ; 0.74,0.25$ to 1.23; $\mathrm{P}=0.010)$. We found small, non-significant differences between film stars who played either
Hospital Clinic, University of Barcelona, 08036 Barcelona, Spain Antoni Trilla director of preventive medicine and epidemiology unit Marta Aymerich consultant, haemopathology unit Antonio M Lacy consultant, general and digestive tract surgery unit Maria J Bertran specialist, preventive medicine and epidemiology unit Correspondence to: A Trilla atrilla@clinic.ub.es

BMJ 2006;333:1291-3 


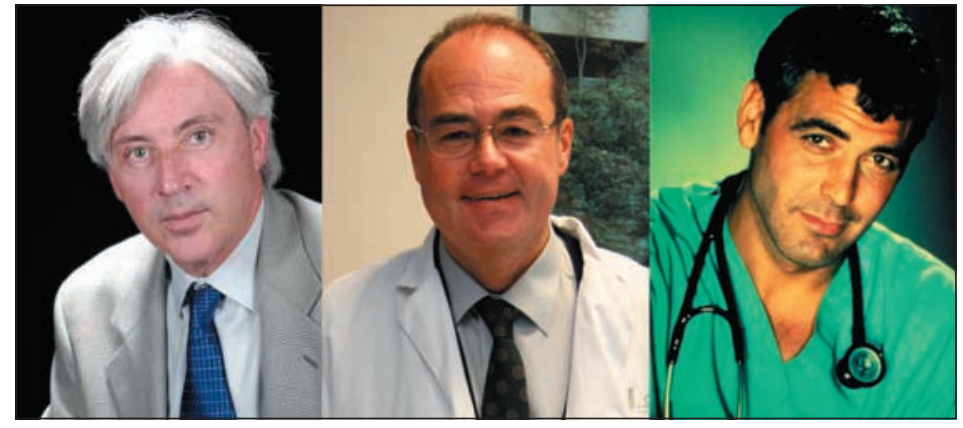

Surgeon, physician, film star

surgeons or physicians. Incidentally, we noted a higher proportion of baldness (surrogate marker) among physicians.

The figure shows a control, a surgeon, and a physician from our study (the physician and surgeon are by chance authors of this study) to provide a snap shot summary of the main study findings.

We did not make individual results public. However, widespread rumours, discussions, polls, and illegal bets arose throughout the institution as a by-product of our study. If they requested, participants were privately told about their personal score compared with the average score of the relevant group.

\section{Discussion}

Our study shows that, on average, senior male surgeons are significantly taller and better looking than senior male physicians. It also shows that film stars who play doctors are significantly better looking than real surgeons and physicians.

\section{Differences between surgeons and physicians}

Perhaps because of their training, surgeons have a different attitude and approach to the practice of medicine compared with physicians. The surgeon's image is that of competence, trust, expertise, and compassion. ${ }^{1}$ Surgeons are the only doctors who practise what has been called "confidence based medicine," which is based on boldness. ${ }^{2}$ They are often practical and fast acting, and they exert tight control on their natural turf-the operating theatre. Being taller and better looking has several evolutionary advantages for surgeons. Their extra height makes them more likely to be masters and commanders, and gives them a better view of the operating room, including the patient lying on the table. Also, as the senior male surgeon is normally surrounded by junior surgical staff, training fellows, nurses, anaesthetists, and the like, his height and appearance make him easily identifiable as their leader.

How do surgeons become taller and better looking than physicians?

There are several potential explanations for the phenotypic changes between surgeons and physicians. Firstly, surgeons spend a lot of time in operating rooms, which are cleaner, cooler, and have a higher oxygen content than the average medical ward, where physicians spend most of their time. Furthermore, surgeons protect (but not always properly) their faces with surgical masks, a barrier to facial microtrauma, and perhaps an effective anti-ageing device (which deserves further testing). They often wear clog-type shoes, a confounding factor that adds $2-3 \mathrm{~cm}$ to their perceived height. The incidental finding that fewer surgeons are bald might be related to these environmental conditions and to the use of surgical caps.

In contrast, senior physicians are surrounded by fewer people in their habitat (the patient's bedside and the office), and they therefore have less need to be easily identified or spotted by families and nurses in the middle of a swarm. Physicians tend to hang heavy stethoscopes around their necks, which bows their heads forward and reduces their perceived height. They also complain of a (clearly abnormal) need to endlessly update their knowledge in accordance with the current evidence based approach to medicine by reading and studying heaps of medical journals; this overload of information further grinds them down. Although a prospective study found that doctor's white coats decrease in weight with increasing seniority, no significant difference was found between the mean weight of physicians' coats and surgeons' coats (1.4v $1.5 \mathrm{~kg})^{3}$

\section{Limitations and future studies}

Firstly, we did not independently assess the height of the study subjects. However, we trust in their honesty and believe that any potential bias would always point in the same direction, as people tend to overestimate rather than underestimate their height. Secondly, we did not check if the submitted photographs had been improved using the latest technology. The members of the evaluating committee know all the study subjects well, and would easily have spotted any gross attempt at cheating (such as submitting photographs taken when the subject was younger or photographs of another person). Thirdly, the evaluation process of the good looking score is subjective, but we have no reliable alternative. The best known alternative published in the literature (asking a mirror, "Mirror, mirror on the wall, who is the fairest of them all?") works only for queens, a notable shortcoming of this test. ${ }^{4}$ Although it is widely known that the mirror always spoke the truth, at present we do not have access to this device (not currently supplied by the Spanish national health system).

Further studies are needed to assess whether our findings also apply to junior male surgeons and physicians, as well as to senior and junior female staff. Currently the number of female surgeons in their $50 \mathrm{~s}$ at our institution is small, and we cannot enrol enough study subjects, a situation that will change no doubt over the next five to 10 years. We believe also that a non-crossover design deserves further testing (good looking score of men evaluated by men and a similar system for women).

\section{Conclusions}

Male surgeons are taller and better looking than physicians, but whether these differences are genetic or environmental is unclear. However, most surgeons and physicians are pleased with their career choices and even with their looks (personal communications). 
Thanks to all participants in our study who provided a breath of fresh air and a touch of humour. Thanks also to the members of the evaluating committee for taking the risk and having some fun together. Finally, thanks to Sarah Lafuente and Beatriz Serrano for help in the statistical analysis.

Contributors: All authors designed the study. MA and MJB designed the good looking score. AT and AML are guarantors. Funding: None

Competing interests: AT is a physician and AML is a surgeon. AT and MA have been happily married for 25 years. MA's good looking score for AT was not requested to avoid any problems at home for Christmas.
Ethical approval: Submitted to the institutional review board (IRB) but transferred for approval by the institutional beauty review (IBR), an ad hoc subcommittee of our institution.

1 Rowland PA, Coe NPW, Burchard KW, Pricolo VE. Factors affecting the professional image of physicians. Curr Surg 2005;62:214-6.

Isaacs D, Fitzgerald D. Seven alternatives to evidence based medicine. $B M J$ 1999;319:1618.

Gordon PM, Keohane SG, Herd RM. White coat effects. BMI 1995;311:1704.

4 Wikipedia. Snow White. http://en.wikipedia.org/wiki/Snow_White.

(Accepted 20 October 2006)

doi $10.1136 /$ bmj.39015.672373.80

\title{
Subcutaneous inflammation mimicking metastatic malignancy induced by injection of mistletoe extract
}

\author{
A I Finall, S A McIntosh, W D Thompson
}

We describe the histological features of subcutaneous inflammation induced by mistletoe, a popular Christmas decoration, when used as an anticancer complementary therapy. We also outline the use of extract of mistletoe in this context

\section{Case report}

A 61 year old woman attending a follow-up appointment two months after excision of tubular carcinoma of the breast complained of an abdominal wall mass. The lesion was subcutaneous, mildly tender, and had a nodular consistency. The patient was worried that the soft tissue mass might be a recurrence of follicular lymphoma, which had been diagnosed in April 2001, although her disease had been stable after five cycles of chemotherapy. The possibility of metastatic breast carcinoma was low considering the good prognostic features of tubular carcinoma.

The lesion was excised and the $4 \times 2 \times 2 \mathrm{~cm}$ mass of subcutaneous tissue seemed to consist solely of fibroadipose tissue. Microscopically, we identified a widespread infiltrate of plasma cells, lymphocytes, and eosinophils within the subcutaneous adipose tissue, in a septal and lobular distribution, indicating inflammation or panniculitisig.

A large proportion of the inflammatory cells were eosinophils. The lymphocytes formed follicular aggregates, particularly adjacent to blood vessels (fig 1). The architecture of these aggregates was benign. The lymphocytes were normal and immunohistochemistry confirmed a normal distribution of T cells and B cells. We found no evidence of light chain restriction, and Bcl-2 immunoreactivity was negative within the follicle centres, confirming the morphological impression of a reactive lymphoid infiltrate with no evidence of follicular lymphoma.

In addition to the perivascular lymphoid aggregates and panniculitis, lymphocytes and eosinophils were seen within small blood vessel walls, indicating vasculitis (fig 2). In summary, we found no evidence of malignancy after the tissue was examined microscopically on multiple levels.
Lobular panniculitis with paraseptal lymphoid follicles and vasculitis are found in lupus panniculitis, which is seen in systemic and discoid lupus erythematosus. ${ }^{1}$ Eosinophils have been reported in up to a quarter of patients with this disorder, making it a possible diagnosis in our patient. ${ }^{2}$ The microscopic features of the subcutaneous inflammation seen in dermatomyositis are indistinguishable from those seen in lupus, but a muscle biopsy would be needed to make such a diagnosis. ${ }^{3}$ Traumatic and factitial panniculitis are characterised by a mixed lobular and septal panniculitis, but they can be excluded in this case because of the absence of fat cyst formation, necrosis, and infiltrates of macrophages and multinucleate giant cells. ${ }^{4}$ Such features are also seen in post-steroid panniculitis, where multiple subcutaneous nodules develop up to a month after cessation of steroids. ${ }^{5}$

Our patient satisfied none of the 11 diagnostic criteria for systemic lupus erythematosus as set out by the American Rheumatism Association. ${ }^{6}$ After discussion with her surgeon, it transpired that the patient had been receiving subcutaneous injections of mistletoe extract as complementary therapy aimed at treating her lymphoma. She used an aqueous, whole plant extract of mistletoe grown on ash trees, called "Abnoba

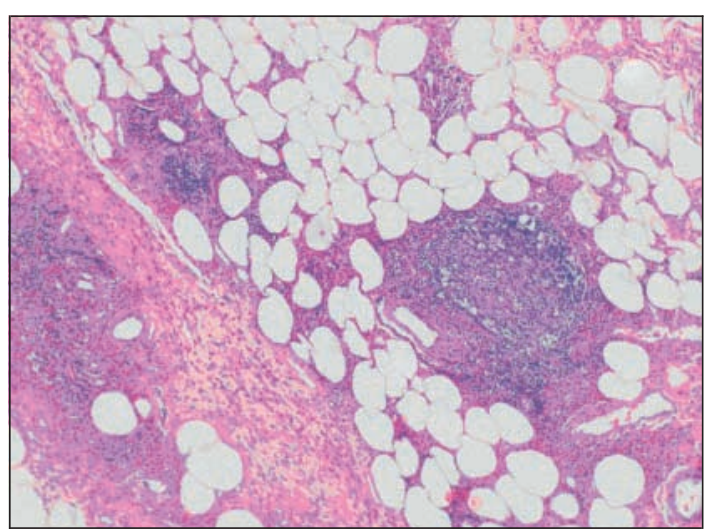

Fig 1 Medium power view ( $\times 200)$ of follicular aggregates of lymphoid cells in a perivascular distribution with a heavy infiltrate of eosinophils in the background
Department of Histopathology, University Hospital of Wales, Cardiff and Vale NHS Trust, Cardiff CF14 4XW A I Finall specialist registrar, histopathology

Unit of Breast Surgery, Aberdeen Royal Infirmary, Aberdeen AB25 2ZD

S A McIntosh consultant surgeon W D Thompson consultant histopathologist Correspondence to: A Finall Alison.Finall@ CardiffandVale.wales. nhs.uk

BMJ 2006;333:1293-4 